\title{
In Vitro Release of Indian Penny Wort, Walnut, and Turmeric from Topical Preparations Using Two Different Types of Membranes
}

\author{
Sonia Khiljee ${ }^{1,2}$, Nisar-Ur-Rehman ${ }^{2}$, Muhammad Khan Sarfraz ${ }^{1}$, Hamid Montazeri', \\ Tanzila Khiljee ${ }^{2}$, and Raimar Löbenberg ${ }^{1, *}$ \\ 'Faculty of Pharmacy and Pharmaceutical Sciences, University of Alberta, AB, Canada \\ ${ }^{2}$ Faculty of Pharmacy and Alternative Medicine, The Islamia University of Bahawalpur, Pakistan
}

\begin{abstract}
Herbal remedies like the Indian penny wort, walnut, and turmeric are useful in traditional medicine for the treatment of many skin diseases, especially eczema. The aim of the present study was to formulate a microemulsion, a gel, and an ointment containing these plant extracts and to evaluate their in vitro release using markers. The in vitro release was assessed using Franz cells and two different types of membranes, nylon and cellulose. The three formulations showed different releases, except for the microemulsion and gel of Indian penny wort and walnut, which had similar release profiles. The study showed that the nylon membrane had a faster release than the cellulose membrane. However, first-order release kinetics for all three formulations were only observed for the cellulose membrane. In this study, the cellulose membrane showed more discriminative power to differentiate among the three tested herbs and their formulations. This demonstrates that it is important to investigate the impact of the membrane on the release pattern of different formulations. In vitro diffusion cell experiments can be used to develop improved formulations of traditional medicines.
\end{abstract}

\section{INTRODUCTION}

M any skin diseases are prevalent in society; among them, eczema is the most common skin disease in hot climate countries. Different types of herbal remedies are used as household treatments for eczema. In Asia pastes of Centella asiatica (Indian penny wort), Juglans nigra (walnut leaves), along with the rhizome of Curcuma longa (turmeric) are topically applied to treat eczema.

Centella asiatica L., fam. Mackinlayoideae, is commonly known as the gotu kola or Indian penny wort. The plant leaves are used as an herbal tea, extracts are used to treat skin problems (1), and poultices are used on open sores. Centella asiatica's ability to aid wound healing was utilized in traditional medicine to treat leprosy using topical dosage forms. Scientific evidence shows that treatment with Centella asiatica activates type I collagen $(2,3)$, which helps the maturation of scar tissue. Centella asiatica can also decrease inflammatory reactions and myofibroblast production. It also has antioxidant properties (4).

Black walnut (Juglans nigra L., fam. Juglandaceae) is used to prepare tea by boiling the leaves in water, and the decoct is used in baths and bandages as well as for topical rinse solutions to treat skin infections. Walnut leaves are traditionally used to treat athlete's foot, eczema, herpes, psoriasis, and different types of skin parasites. Astringent tannins are important ingredients of walnut leaves. These tannins cross-link with the skin cells enabling them to be more resistant to microorganisms (5). In

${ }^{*}$ Corresponding author. addition, high concentrations of vitamin C are found in walnut leaves $(6,7)$.

Curcuma longa L. (fam. Zingiberaceae), also known as turmeric, is used as a household remedy for many diseases. Turmeric has anti-inflammatory and antioxidant effects. Traditionally, turmeric powder is mixed with sweet lime juice and salt to treat sprained ankles. It is reported that a paste gives quick and long-lasting relief. Other traditional uses include sprinkling the powder on wounds or ulcers to increase healing. Turmeric is an antiseptic (8) and stops bleeding and is used for cuts or burns (4).

The aim of the present study was to prepare three dosage forms, a microemulsion, a gel, and an ointment, using these herbal plant extracts and evaluate their release from the topical preparations using Franz cells. Two types of membranes, nylon and cellulose, were evaluated to determine if differences between their discriminative properties exist. Drug release from three topical preparations containing traditional remedies was investigated.

\section{MATERIALS \\ Chemicals}

Curcumin was chosen as the analytical standard for turmeric and was purchased from PCCA (London, ON). The analytical markers for walnut and Indian penny wort were juglone and asiaticoside, respectively. Hard paraffin, wool fat, cetostearyl alcohol, and white soft paraffin were purchased from Sigma Aldrich. Oleic acid was from Merck, Germany. Carbopol P934 was obtained from Wilson 
Islamabad, Pakistan. Acetonitrile, methanol, acetone, disodium hydrogen phosphate, potassium dihydrogen phosphate, triethanolamine, and ethanol (95\%) were purchased from Caledon. Glacial acetic acid and Polysorbate 20 were from Fisher Scientific. Nylon membrane filter (hydrophobic, $0.22 \mu \mathrm{m}, 125-\mu \mathrm{m}$ thickness, and 25-mm diameter) and mixed cellulose ester membrane filter (hydrophilic, $0.025 \mu \mathrm{m}, 180-\mu \mathrm{m}$ thickness, and $25-\mathrm{mm}$ diameter) were obtained from Millipore Corp.

\section{Preparation of Apparatus and Sampling}

The experimental setup for all experiments included six Franz diffusion cells with open caps and flat ground glass with an orifice diameter of $15 \mathrm{~mm}$ and a receiver volume of about $12 \mathrm{~mL}$. The temperature of the receiver medium was maintained at $32.5^{\circ} \mathrm{C}$ using a circulating thermostated bath (Haakel D2). The receptor medium was stirred using a magnetic stirrer at $600 \mathrm{rpm}$ (IKA). The top of the Franz cell was covered with a membrane, and the open cap was fixed on the Franz cell with a clamp. The system was allowed to equilibrate for at least $30 \mathrm{~min}$. The receptor medium was composed of $60 \mathrm{~mL}$ USP alcohol and $140 \mathrm{~mL}$ of water (9). The medium was filtered through a 47- $\mathrm{mm}$ diameter, $0.45-\mu \mathrm{m}$ membrane via vacuum to degas the solution. The test was started after $500 \mathrm{mg}$ of formulation was added to the top of the membrane via a syringe. At each sampling time point, $0.5-\mathrm{mL}$ samples were collected through the sampling port using a $1-\mathrm{mL}$ syringe. The stirring was stopped when samples were taken and resumed afterward. Sampling time points were 0.5, 1, 2, 3, $4,5,6,12$, and $24 \mathrm{~h}$ for the test preparations. The withdrawn medium was replaced with fresh medium. The calculation was adjusted for the withdrawn amounts (10). HPLC assays were used to quantify the samples (9).The HPLC system was equipped with a Shimadzu LC 600 pump, a Jasco UV/ VIS detector, and a Jasco 851-AS autosampler. Clarity software (DataApex) was used for data acquisition. The analytical column was a reversed-phase $C 18$ Lichrospher 100 RP-18 column, $125 \times 4.6 \mathrm{~mm}$ (Merck).

\section{Indian Penny Wort}

The mobile phase consisted of acetonitrile, methanol, and water (22:28:50) and was degassed before use. The detection of asiaticoside, a marker for penny wort, was performed at $204 \mathrm{~nm}$; the flow rate was $0.8 \mathrm{~mL} / \mathrm{min}$ (11). Asiaticoside stock solution was made using methanol. The calibration curve had a range of $0.03125-0.5 \mathrm{mg} / \mathrm{mL}$ and a regression coefficient of 0.996 . The quantification of the marker in the plant extract was performed by dissolving $0.5 \mathrm{~g}$ of extract in methanol. The retention time for asiaticoside was $6.1 \mathrm{~min}$. Each formulation contained 5\% $(\mathrm{w} / \mathrm{w})$ plant extract, and the test sample of $0.5 \mathrm{~g}$ of each Indian penny wort extract formulation contained $0.53 \mathrm{mg}$ of asiaticoside.

\section{Walnut}

The analytical assay of walnut was performed as described by Hadjmohammadi et al. (12). The mobile phase was acetonitrile and $\mathrm{pH} 4.0$ phosphate buffer (50:50). UV detection was at $250 \mathrm{~nm}$ and the flow rate was $0.9 \mathrm{~mL} / \mathrm{min}$. The phosphate buffer was made by dissolving $8.9 \mathrm{~g}$ of disodium hydrogen phosphate and $3.4 \mathrm{~g}$ of potassium dihydrogen phosphate in one liter of distilled water. The mobile phase was degassed before use. Juglone standard solutions were made in acetonitrile in the range of $0.3125-5 \mathrm{mg} / \mathrm{mL}$, and the standard curve had a regression coefficient of 0.994 . The amount of juglone in the extract was determined by dissolving $0.5 \mathrm{~g}$ of extract in acetonitrile. The retention time for juglone was $4.0 \mathrm{~min}$. Each formulation contained $5 \%(\mathrm{w} / \mathrm{w})$ plant extract, and the test sample of $0.5 \mathrm{~g}$ of each walnut extract formulation contained $0.888 \mathrm{mg}$ of juglone.

\section{Turmeric}

The analytical assay for turmeric was followed as described by Heath et al. (13). The mobile phase contained acetonitrile, methanol, water, and glacial acetic acid 40:35:24:1 with a $\mathrm{pH}$ of 4.1. UV detection was at $246 \mathrm{~nm}$ and the flow rate was $0.9 \mathrm{~mL} / \mathrm{min}$. A curcumin standard solution was made in acetone in concentrations of $0.3125-5 \mathrm{mg} / \mathrm{mL}$. The regression coefficient of the standard curve was 0.995 . The amount of curcumin in the extract was determined by dissolving $0.5 \mathrm{~g}$ extract in acetonitrile. The retention time of curcumin was $2.7 \mathrm{~min}$. Each formulation contained $5 \%(\mathrm{w} / \mathrm{w})$ plant extract, and the test sample of $0.5 \mathrm{~g}$ of each formulation of tumeric extract contained $0.5 \mathrm{mg}$ of curcumin.

\section{Preparation of a Microemulsion}

The microemulsion was prepared as described by Chen et al. (14). A surfactant mixture was prepared by manually mixing polysorbate 20 and ethanol as surfactant and cosurfactant, respectively, in a 2:1 ratio. A 4.6-g aliquot of the surfactant mixture was added to $0.5 \mathrm{~g}$ of oleic acid (oil) and mixed vigorously with magnetic stirring. Plant extracts $(0.5 \mathrm{~g})$ were added to the surfactant mixture and then into oleic acid and stirred until completely dissolved.Then $4.4 \mathrm{~g}$ of filtered, deionized water was added gradually under constant stirring (1200 rpm) at ambient temperature.

\section{Preparation of a Carbopol Gel}

A carbopol gel was prepared as described by Proniuk et al. (15). Carbopol 934P was gradually dissolved in distilled water under constant stirring (1200 rpm) at ambient temperature to make a $1 \%$ solution. Triethanolamine was added dropwise until a gel formed; the gel had a $\mathrm{pH}$ of 5.3. The $0.5-\mathrm{g}$ plant extracts were added, then $\mathrm{pH}$ was determined. Indian penny wort gel had a $\mathrm{pH}$ of 5.5 , walnut gel a pH of 6.2, and turmeric gel a pH of 5.6.

\section{Preparation of Ointment}

Simple Ointment BP was prepared by melting $4.75 \mathrm{~g}$ of hard paraffin at $60^{\circ} \mathrm{C}$, to which $4.75 \mathrm{~g}$ of wool fat was added, followed by $4.75 \mathrm{~g}$ cetostearyl alcohol. The 

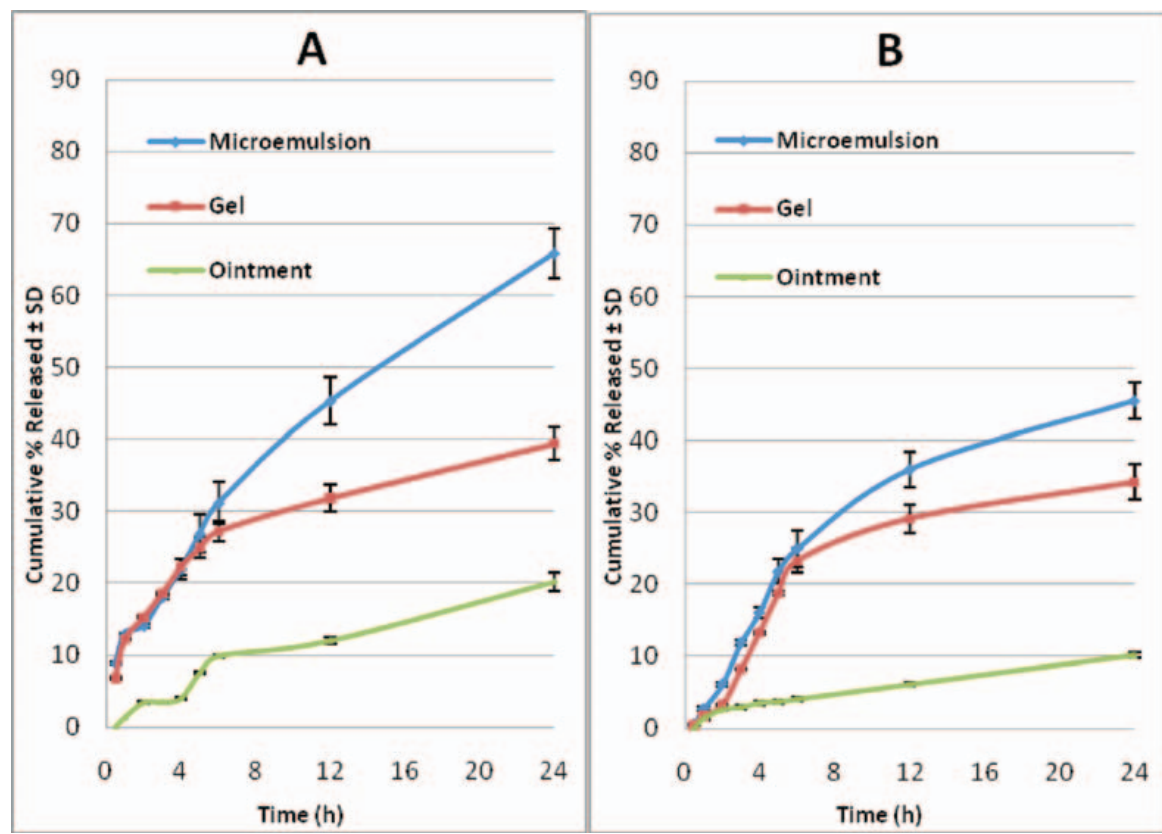

Figure 1. Comparison of the release profiles of asiaticoside from three dosage forms containing Indian penny wort using (A) nylon and (B) cellulose membrane.

ointment was cooled and stirred until it reached room temperature. White soft paraffin $(80.75 \mathrm{~g})$ and $5 \mathrm{~g}$ extract were added (16)

\section{Statistical Analysis}

Wilks Lambda two-way multivariate ANOVA was used to compare the effect of the cellulose and nylon membranes using SPSS 18 software (17). For the comparison of the formulations, the $f_{2}$ factor analysis was used (18). The release data of all formulations were fit to a first-order release model $(19,20)$ and then compared with one other. Flux $(J)$ was calculated as $\mu \mathrm{g} / \mathrm{h} / \mathrm{cm}^{2}(21,22)$.

\section{RESULTS}

\section{Comparison of Three Dosage Forms of Indian} Penny Wort

Samples $(500 \mathrm{mg}$ ) of topical formulations containing Indian penny wort extract were tested using both types of membranes. Figure 1 shows the release profiles of asiaticoside from three dosage forms. The microemulsion and the gel showed two distinct release patterns for both membranes. For the nylon membrane, both formulations showed similarity in their release patterns $\left(f_{2}=83.29\right)$ when compared in the first $6 \mathrm{~h}$ (Table 1). However, after $6 \mathrm{~h}$ their release patterns were not similar $\left(f_{2}=49.82\right)$. The cellulose membrane showed similar release patterns for the microemulsion and the gel up to $24 \mathrm{~h}\left(f_{2}=65.02\right)$, and the release data fit well to a first-order model. The ointment showed four different release rates within $24 \mathrm{~h}$ when the nylon membrane was used. The $f_{2}$ was below 50 when compared with the other formulations. A first-order release from the ointment was observed when the cellulose membrane was used. The $p$ values corresponding to the Wilks Lambda statistics show that the nature of the membrane had a significant impact on the release profiles of tested formulations.

\section{Comparison of Three Dosage Forms of Walnut}

Samples $(500 \mathrm{mg}$ ) of topical formulations containing walnut extract were tested using both types of membranes. Figure 2 shows the release profiles of juglone from three dosage forms. Both membranes were able to differentiate among the different formulations within $24 \mathrm{~h}$. For the nylon membrane, it was observed in the first $6 \mathrm{~h}$ that the release profiles from the microemulsion and gel were similar $\left(f_{2}=68.37\right)$. The release profile for the ointment with the nylon membrane was first-order but was not similar to the other formulations. The cellulose and nylon membranes showed similar release profiles. However, the cellulose membrane was better able to differentiate among the different formulations. The corresponding $f_{2}$ values are given in Table 1. The $p$ values corresponding to the Wilks Lambda statistics for the walnut formulations show that the nature of the membrane had significant impact on the release profiles.

\section{Comparison of Three Dosage Forms of Turmeric}

Samples $(500 \mathrm{mg})$ of topical formulations containing tumeric extract were tested using both types of membranes. Figure 3 shows the release profiles of curcumin from the three tested dosage forms. As shown in Figure 3, the microemulsion and the gel exhibited changes in their marker release profiles over $24 \mathrm{~h}$ with the nylon membrane. Additionally, the ointment released its content 
Table 1.f Factor Analysis for Three Dosage Forms of Indian Penny Wort, Walnut, and Turmeric (from 0-24 h)

\begin{tabular}{|c|c|c|c|c|}
\hline \multirow[t]{2}{*}{ Formulation } & \multicolumn{2}{|c|}{ Nylon membrane } & \multicolumn{2}{|c|}{ Cellulose membrane } \\
\hline & $0-6 \mathrm{~h}$ & $0-24 \mathrm{~h}$ & $0-6 \mathrm{~h}$ & $0-24 \mathrm{~h}$ \\
\hline \multicolumn{5}{|c|}{$f_{2}$ factor analysis for Indian penny wort } \\
\hline Microemulsion vs.gel & 83.29 & 49.82 & 78.87 & 65.02 \\
\hline $\begin{array}{l}\text { Microemulsion vs. } \\
\text { ointment }\end{array}$ & 40.40 & 31.61 & 45.92 & 36.35 \\
\hline Gel vs. ointment & 41.90 & 40.09 & 49.59 & 42.25 \\
\hline \multicolumn{5}{|c|}{$f_{2}$ factor analysis for walnut } \\
\hline Microemulsion vs.gel & 68.37 & 60.31 & 60.03 & 51.38 \\
\hline $\begin{array}{l}\text { Microemulsion vs. } \\
\text { ointment }\end{array}$ & 40.41 & 34.70 & 47.09 & 40.30 \\
\hline Gel vs. ointment & 45.86 & 41.78 & 59.04 & 56.82 \\
\hline \multicolumn{5}{|c|}{$f_{2}$ factor analysis for turmeric } \\
\hline Microemulsion vs.gel & 52.52 & 47.24 & 62.06 & 55.01 \\
\hline $\begin{array}{l}\text { Microemulsion vs. } \\
\text { ointment }\end{array}$ & 50.13 & 31.03 & 60.78 & 44.52 \\
\hline Gel vs. ointment & 63.59 & 41.10 & 78.65 & 60.28 \\
\hline
\end{tabular}

faster than the gel in the first $4 \mathrm{~h}$. The ointment release in the first $6 \mathrm{~h}$ was similar to that of the microemulsion $\left(f_{2}=50.13\right)$, but after $24 \mathrm{~h}$ it was no longer similar $\left(f_{2}=31.03\right)$. The ointment showed a first-order release with both membranes. With the cellulose membrane, the microemulsion and the ointment also had similar release patterns in the first $6 \mathrm{~h}\left(f_{2}=60.78\right)$ but not by $24 \mathrm{~h}$ $\left(f_{2}=44.52\right)$. The ointment and gel had similar release patterns up to $24 \mathrm{~h}$ according to the $f_{2}$ comparison $\left(f_{2}=60.28\right)$. The $p$ values corresponding to the Wilks Lambda statistics show that the nature of the membrane had a significant impact on the release profiles of the test formulations.

\section{DISCUSSION}

The investigation of release patterns from topical formulations is not new, but there are only a few studies that investigate the release of markers from traditionally used medicinal plants. In the present study, markers were used as surrogates for the entire extract. As seen in the graphs, at least two distinct release profiles for the microemulsion and gel were obvious within $24 \mathrm{~h}$, one from 0 to $6 \mathrm{~h}$ and one from 6 to $24 \mathrm{~h}$. After $6 \mathrm{~h}$, it was observed that the microemulsion was diluted by the receptor medium, and the gel began to swell. This was most prominent when the nylon membrane was used. The often-observed change in the release profiles after $6 \mathrm{~h}$ might be due to this dilution factor or to the solubility of markers in the receptor medium. An observation time of $6 \mathrm{~h}$ seemed to be sufficient to assess the release from the three formulations. This period would avoid undesirable effects, which might not be dosage-form related.

In this study, two types of membranes $(0.22-\mu \mathrm{m}$ nylon membrane and $0.025-\mu \mathrm{m}$ cellulose membrane) were used. Table 2 shows that the nylon membrane had the highest


Figure 2. Comparison of the release profiles of juglone from three dosage forms containing walnut using (A) nylon membrane and (B) cellulose membrane. 

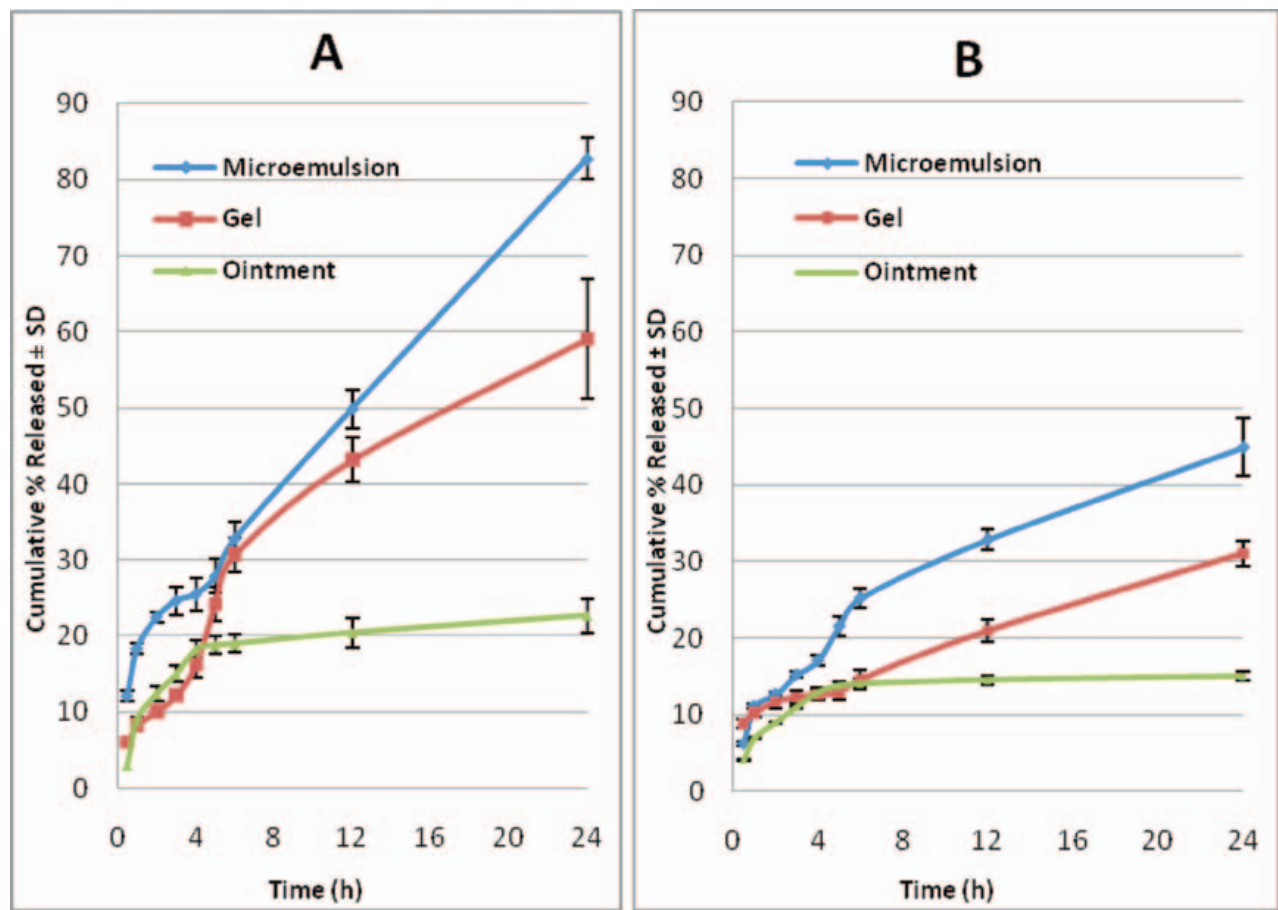

Figure 3. Comparison of the release profiles of curcumin from three dosage forms containing turmeric using (A) nylon membrane and (B) cellulose membrane.

flux (23) for all formulations compared with the cellulose membrane. This might be due to the thickness of $125 \mu \mathrm{m}$ and the porous nature of the membrane (24). The cellulose membrane was $180 \mu \mathrm{m}$ thick and had 10-fold smaller pores. It was statistically observed that both membranes impacted the marker release differently $(p<0.05)$. This study is consistent with previous works of Clement et al. (25) who described the release of caffeine from water-inoil emulsions and alcoholic gels. Here the nature of the membrane also affected the release. In another study, a nylon membrane gave better results compared with a Sil-Tec membrane as reported by Gallagher et al. (24).

The factors that influence the release from a topical dosage form are the concentration of the marker in the vehicle, solubility of the marker in the vehicle, diffusion coefficient of the marker in the vehicle, partition coefficient of the marker between the vehicle and membrane, and the nature of the membrane including thickness and pore size. In this study, the membrane with the smaller pore size had more discriminatory power to differentiate among the tested formulations. More studies are needed to conclude if the observed differences were only an effect of pore size or if the nature of the membrane material also contributed to the discriminatory power.

\section{CONCLUSION}

The study demonstrated that in vitro release experiments using Franz cells were successfully applied to traditional medicinal extracts. The three formulations showed different release rates, except for the microemulsion and gel of Indian penny wort and walnut, which had similar release profiles. The microemulsion had the fastest release through both membranes compared with the gel or ointment. Statistical analysis proved that both membranes had a significant impact on the marker release. The cellulose membrane showed first-order release for all three herbs and formulations. This membrane had more discriminative power to differentiate among formulations

Table 2. Flux Values of Formulations

\begin{tabular}{|c|c|c|c|c|c|c|}
\hline \multirow[t]{2}{*}{ Formulations } & \multicolumn{2}{|c|}{ Indian Penny Wort } & \multicolumn{2}{|c|}{ Walnut } & \multicolumn{2}{|c|}{ Turmeric } \\
\hline & $\begin{array}{c}\text { Nylon membrane } \\
\mu \mathrm{g} / \mathrm{cm}^{2} / \mathrm{h}\end{array}$ & $\begin{array}{l}\text { Cellulose membrane } \\
\qquad \mathrm{gg} / \mathrm{cm}^{2} / \mathrm{h}\end{array}$ & $\begin{array}{c}\text { Nylon membrane } \\
\mu \mathrm{g} / \mathrm{cm}^{2} / \mathrm{h}\end{array}$ & $\begin{array}{l}\text { Cellulose membrane } \\
\qquad \mathrm{g} / \mathrm{cm}^{2} / \mathrm{h}\end{array}$ & $\begin{array}{c}\text { Nylon membrane } \\
\mu \mathrm{g} / \mathrm{cm}^{2} / \mathrm{h}\end{array}$ & $\begin{array}{l}\text { Cellulose membrane } \\
\mu \mathrm{g} / \mathrm{cm}^{2} / \mathrm{h}\end{array}$ \\
\hline Microemulsion & 6.13 & 3.55 & 6.63 & 5.64 & 8.40 & 3.31 \\
\hline Gel & 2.21 & 1.91 & 3.37 & 3.31 & 4.71 & 2.75 \\
\hline Ointment & 1.90 & 1.09 & 2.17 & 1.80 & 0.66 & 0.19 \\
\hline
\end{tabular}


and should be used for future studies. This demonstrates that it is important to investigate the impact of the membrane on the release pattern of different formulations. In vitro diffusion cell experiments can be used to develop improved formulations of traditional medicines.

\section{ACKNOWLEDGMENTS}

The authors would like to thank the Higher Education Commission of Pakistan for funding the study at Faculty of Pharmacy and Pharmaceutical Sciences, University of Alberta, Edmonton, AB, Canada.

\section{REFERENCES}

1. Widgerow, A. D.; Chait, L. A.; Stals, R.; Stals, P.J. New innovations in scar management. Aesthet. Plast. Surg. 2000, 24 (3), 227-234.

2. Bonte, F.; Dumas, M.; Chaudagne, C.; Meybeck, A. Influence of asiatic acid, madecassic acid, and asiaticoside on human collagen I synthesis. Planta Med. 1994, $60(2), 133-135$.

3. Bonte, F.; Dumas, M.; Chaudagne, C.; Meybeck, A. Comparative activity of asiaticoside and madecassoside on type I and III collagen synthesis by cultured human fibroblasts. Ann. Pharm. Fr. 1995, 53 (1), 38-42.

4. Major Herbs of Ayurveda; Williamson, E. M., Ed.; Churchill Livingstone: New York, 2002; pp 102-117.

5. Pereira, J. A.; Oliveira, I.; Sousa, A.; Valentao, P.; Andrade, P. B.; Ferreira, I. C. Walnut (Juglans regia L.) leaves: Phenolic compounds, antibacterial activity and antioxidant potential of different cultivars. Food. Chem. Toxicol. 2007, 45 (11), 2287-2295.

6. Covey, H.C. African American Slave Medicine: Herbal and Non-Herbal Treatments, 2nd ed.; Lexington Books: Lanham, MD, 2008; 115.

7. Wolfe, F. A. The Complete Idiot's Guide to Herbal Remedies; Alpha Books: Indianapolis, IN, 1999; pp 153-165.

8. The Molecular Targets and Therapeutic Uses of Curcumin in Health and Disease; Aggarwal, B. B., Surh, Y.-J. Shishodia, S., Eds.; Advances in Experimental Medicine and Biology; Springer: New York, 2007; Vol. 595, pp 105-343.

9. Ueda, C.T; Shah, V. P.; Derdzinski, K.; Ewing, G.; Flynn, G.; Maibach, H.; Marques, M.; Rytting, H.; Shaw, S.; Thakker, K.; Yacobi, A. Topical and Transdermal Drug Products. Pharm. Forum 2009, 35 (3), 750-759.

10. Shah, V.P.; Shaw, S. W.; Norton, D. D. In Vitro Telease: Collaborative Study Using the Vertical Diffusion Cell. Pharm. Forum 2006, 32 (5), 1590-1596.

11. Gotu Kola Powder Extract. Cactus Botanics Limited product information Web site. http://www. cactusbotanics.com/Products/Gotukola.htm (accessed Oct 11, 2010).

12. Hadjmohammadi, M. R.; Kamel, K. Determination of Juglone (5-hydroxy 1,4-naphthoquinone) in
Pterocarya fraxinifolia by RP-HPLC. Iran. J. Chem. Chem. Eng. 2006, 25 (4), 73-76.

13. Heath, D. D.; Pruitt, M. A.; Brenner, D. E.; Rock, C. L. Curcumin in plasma and urine: quantitation by high-performance liquid chromatography. J. Chromatogr. B 2003, 783 (1), 287-295.

14. Chen, H.; Chang, X.; Du, D.; Li, J.; Xu, H.; Yang, X. Microemulsion-based hydrogel formulation of ibuprofen for topical delivery. Int. J. Pharm. 2006 , $315(1-2), 52-58$

15. Proniuk, S.; Dixon, S. E.; Blanchard, J. Investigation of the utility of an in vitro release test for optimizing semisolid dosage forms. Pharm. Dev. Technol. 2001, $6(3), 469-476$.

16. Marriott, J. F.; Wilson, K. A.; Langley, C. A.; Belcher, D. Pharmaceutical Compounding and Dispensing; Pharmaceutical Press: London, 2006; p 162.

17. Yuksel, N.; Kanik, A. E.; Baykara, T. Comparison of in vitro dissolution profiles by ANOVA-based, modeldependent and -independent methods. Int.J. Pharm. 2000, 209, 57-67.

18. Gohel, M. C.; Sarvaiya, K. G.; Mehta, N. R.; Soni, C. D.; Vyas, V.U.; Dave, R. K. Assessment of Similarity Factor Using Different Weighting Approaches. Dissolution Technol. 2005, 12 (4), 22-27.

19. Xu, G.; Sunada, H. Influence of formulation change on drug release kinetics from hydroxypropylmethylcellulose matrix tablets. Chem. Pharm. Bull. (Tokyo) 1995, 43 (3), 483-487.

20. Sarfraz, M. K.; Ur-Rehman, N.; Ahmed, S.; Ashraf, M.; Mohsin, S. Ethyl Cellulose-Based Solid Matrix System for Sustaining Release of Naproxen. Pak. J. Biol. Sci. 2007, 10 (4), 668-672.

21. Özgüney, I. S.; Karasulu, H.Y.; Kantarci, G.; Sözer, S.; Güneri, T.; Ertan, G. Transdermal Delivery of Diclofenac Sodium Through Rat Skin From Various Formulations. AAPS PharmSciTech 2006, 7 (4), Article 88.

22. Kreilgaard, M.; Pederson, E. J.; Jaroszewski, J.W. NMR characterisation and transdermal drug delivery potential of microemulsion systems. J. Control. Release 2000,69 (3), 421-433.

23. Ng, S.-F.; Rouse, J.; Sanderson, D.; Eccleston, G. A Comparative Study of Transmembrane Diffusion and Permeation of Ibuprofen across Synthetic Membranes Using Franz Diffusion Cells. Pharmaceutics 2010, 2, 209-223.

24. Gallagher, S. J.; Trottet, L.; Carter, T. P.; Heard, C. M. Effects of membrane type and liquid/liquid phase boundary on in vitro release of ketoprofen from gel formulations. J. Drug Target. 2003, 11 (6), 373-379.

25. Clement, P.; Laugel, C.; Marty, J. P. Influence of three synthetic membranes on the release of caffeine from concentrated W/O emulsions. J. Control. Release 2000, $66(2-3), 243-254$ 